\title{
Spatial representativity of air-temperature information from instrumental and ice-core-based isotope records in the European Alps
}

\author{
Wolfgang SCHÖNER, ${ }^{1}$ Ingeborg AUER, ${ }^{1}$ Reinhard BÖHM,,${ }^{1}$ Lothar KEGK, ${ }^{2}$ \\ Dietmar WAGENBACH ${ }^{2}$ \\ ${ }^{1}$ Central Institute for Meteorology and Geodynamics, Hohe Warte 38, A-1190 Vienna, Austria \\ Email:wolfgang.schoener@zamg.ac.at \\ ${ }^{2}$ Institut für Umweltphysik, University of Heidelberg, Im Neuenheimer Feld 229, D-69120 Heidelberg, Germany
}

\begin{abstract}
Spatial correlations between Alpine high-elevation and European lowelevation instrumental air temperatures are computed to assess the spatial representativity of a high-Alpine ice-core isotope proxy temperature record. The correlation analyses indicate that air-temperature records at Alpine ice-core drill sites are representative for central Europe, particularly in summer. While Alpine ice cores generally show a large scattering in the conserved section of the year, long-term records from low-accumulation sites consist almost solely of summer precipitation and thus reflect isotope proxy summertemperature variability. However, correlation between seasonal and annual instrumental air temperature indicates that summer temperature variability provides an adequate approach to annual temperature variability. Comparison of long-term ice-core $\delta^{18} \mathrm{O}$ records from Colle Gnifetti (4450 m a.s.l.), Monte Rosa, Western Alps, with local instrumental summer temperatures inferred from an instrumental network shows good agreement in the long-term scale. Thus Alpine long-term ice-core $\delta^{18} \mathrm{O}$ records are representative for central European air-temperature variability.
\end{abstract}

\section{INTRODUCTION}

Stable-water-isotope ice-core records from vast polar ice sheets are a well-recognized proxy for local condensation temperature (Jouzel and others, 1997). However, a major difference between the precipitation-sampling systems of polar ice sheets and mid-latitude ice-core sites must be stressed. Since the required cold-temperature regime at mid-latitude sites is maintained only at high altitude, the drill-site area will be relatively small and situated at an exposed (strongly wind-influenced) location. Consequently, several mid-latitude drill sites, such as in the European Alps, are subject to a substantial net loss of surface snow, especially during winter, rendering the ice-core records seasonally unrepresentative (Wagenbach, 1994).

When evaluating Alpine ice-core records, it is important to remember that the long-term net snow-accumulation rate is controlled by the upstream surface condition (Alean and others, 1984), making the conserved seasonal fraction of total precipitation systematically variable in space and time (examination of the impact of this effect is beyond the scope of this paper).

As with polar drill sites, a basic problem of stable-waterisotope records from Alpine sites concerns the spatial representativity of a given local temperature proxy signal. In the Alps this question is linked to the seasonal representativity of such ice-core records. The impact of climate-changeinduced seasonality changes on the representativity of the recorded Alpine proxy temperature is discussed elsewhere (Auer and others, 2001b). Consequently, investigations into the spatial representativity of a potentially recorded local temperature signal at drill sites are to be evaluated for different seasons. It is also necessary to evaluate to what extent seasonal temperature records may reflect mean annual temperature variability, which is one of the key parameters in climate research.

To tackle these questions, within the European Union project ALPCLIM (focusing, among other things, on the extension of Alpine climate records beyond the instrumental period by Alpine ice-core proxies (Wagenbach and others, 1998), spatial correlation between instrumental air-temperature series is used to determine the spatial representativity of the ice-core stable-isotope-derived air-temperature signal. To overcome the problem of seasonal selectivity of ice-core records, the evaluation is divided into a summer and a winter period. The study underlines the favourable situation existing in Europe, where a dense network of long-term, welldocumented instrumental climate records is available.

\section{INSTRUMENTAL TEMPERATURE DATA}

The network of Alpine long-term temperature time series was used to elaborate carefully homogenized gridded series of relative temperature changes in monthly resolution (Böhm and others, 2001). The dataset covers the region $43-49^{\circ} \mathrm{N}, 4$ $18^{\circ} \mathrm{E}$ with $1^{\circ}$ latitude/longitude spatial resolution and dates back to 1765 (hereafter denoted as ALPCLIM dataset). To consider vertical differences of Alpine climate variability the ALPCLIM series have been subdivided into high-elevation $(>1500 \mathrm{~m}$ a.s.l.) and low- elevation temperature series 

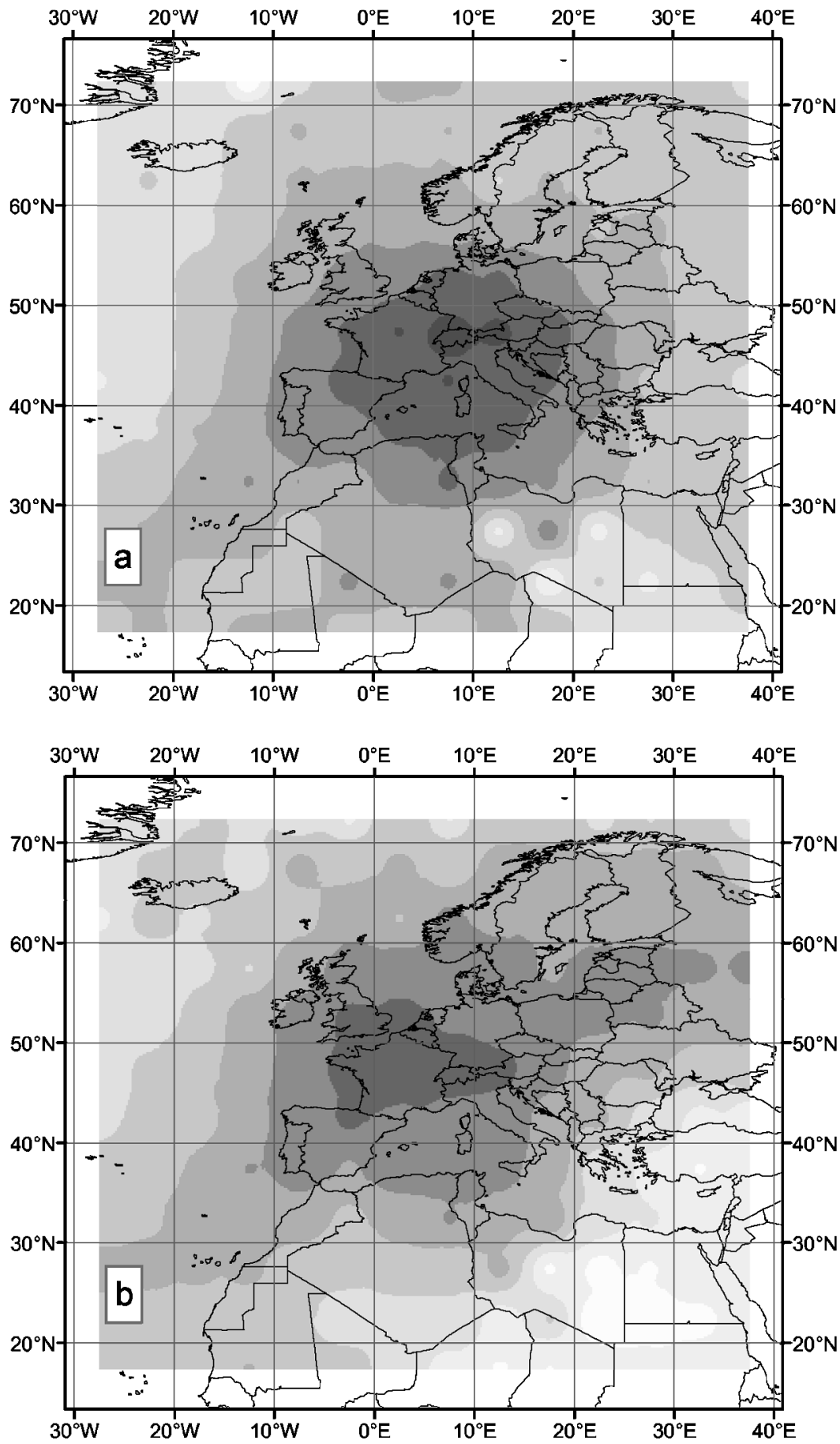

$-0.6--0.4$

$-0.4--0.2$

$-0.2--0$

$0-0.2$

$0.2-0.4$

$0.4-0.6$

$0.6-0.8$

$0.8-0.9$

Fig. 1. Spatial correlation between ALPCLIM Colle Gnifetti temperature and European-wide CRU time series, 1901-98, (a) for summer means (April-September), (b) for winter means (October-March).

(hereafter denoted as ALPCLIM HE and ALPCLIM LE datasets, respectively).

Since there are no continuous long-term temperature measurements at the Colle Gnifetti (4450 ma.s.l.; Monte Rosa, Western Alps) drill site, this temperature series was computed as described by Auer and others (2001b) from the nearest ALPCLIM HE gridpoint $\left(46^{\circ} \mathrm{N}, 8^{\circ} \mathrm{E}\right.$, representing approximately the central summit range of the Western Alps) temperature (hereafter denoted as CG instrumental air temperature). This air-temperature series dates back to 1818 .
To assess the European-scale spatial representativity of CG air-temperature series, the gridded temperature dataset of the Climatic Research Unit (CRU), University of East Anglia, U.K., which was derived from lowland station data (Jones, 1994), is used as this is the only temperature series completely covering Europe and the data passed some homogeneity testing. As a compromise between the spatial coverage of Europe and gridbox data completeness we selected the region $75^{\circ} \mathrm{N}$, $30^{\circ} \mathrm{W}$ to $15^{\circ} \mathrm{N}, 35^{\circ} \mathrm{E}$ ( $5^{\circ}$ latitude/longitude gridbox spatial resolution) from the $\mathrm{CRU}$ database (hereafter denoted as 


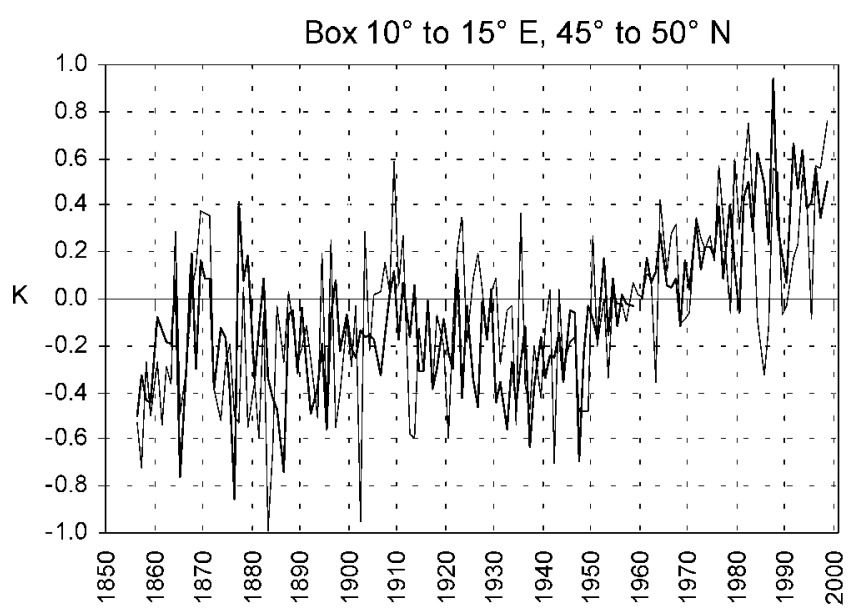

Fig. 2. Difference between the CRU and the ALPCLIM temperature series (ALPCLIM minus CRU) for common gridbox 10/15E 45/50N (bold line: summer; thin line: winter).

CRU dataset). For comparison of the GRU and ALPCLIM datasets, the ALPCLIM dataset was upscaled from $1^{\circ}$ gridpoint resolution to $5^{\circ}$ gridbox resolution.

The importance of climate-data homogenization (station relocations, instrumental alterations, etc.) for climate-change studies is discussed by, among others, Moberg and Alexandersson (1997), Peterson and others (1998) and Auer and others (1999). Within this study the influence of possible inhomogeneities of the deployed CRU temperature time series is assessed against the extensively homogenized time series of the ALPCLIM LE dataset.

\section{Spatial representativity of alpine air-temperature signal}

Pearson's correlation coefficient provides a good measure of the coincidence of time series in high-frequency variability (e.g. year-to-year changes). A high correlation also indicates a low-frequency coincidence (e.g. on the multi-decadal timescale).

Taking mean temperatures of individual winters (OctoberMarch) and of individual summers (April-September) within the time period 1901-98, the correlation between each CRU gridbox and the CG instrumental air temperatures was calculated. Gridbox correlations were transferred to maps by means of an inverse distance-weighting interpolation procedure (as implemented in geographic information system software ArcView).

The correlation fields displayed in Figure la and b clearly indicate the generally high spatial persistence of the highelevation Alpine air-temperature signal for central European lowland sites, for both the summer and winter periods. This finding is confirmed by Auer and others (2001a) who showed that a high correlation not only between high-elevation Alpine sites but also between high-elevation and lowland sites may be expected. As seen in the maps, in summer the spatial extension of the high-correlation category is larger, and the correlation between high-altitude temperatures and lowAlpine temperatures generally higher, than in winter. The weaker winter correlation can be explained by the decoupling of lowland areas from high-level sites due to temperatureinversion weather patterns. While the summer does not show a predominant direction in the temperature-signal persistence, the winter is dominated by an enhanced temperature-
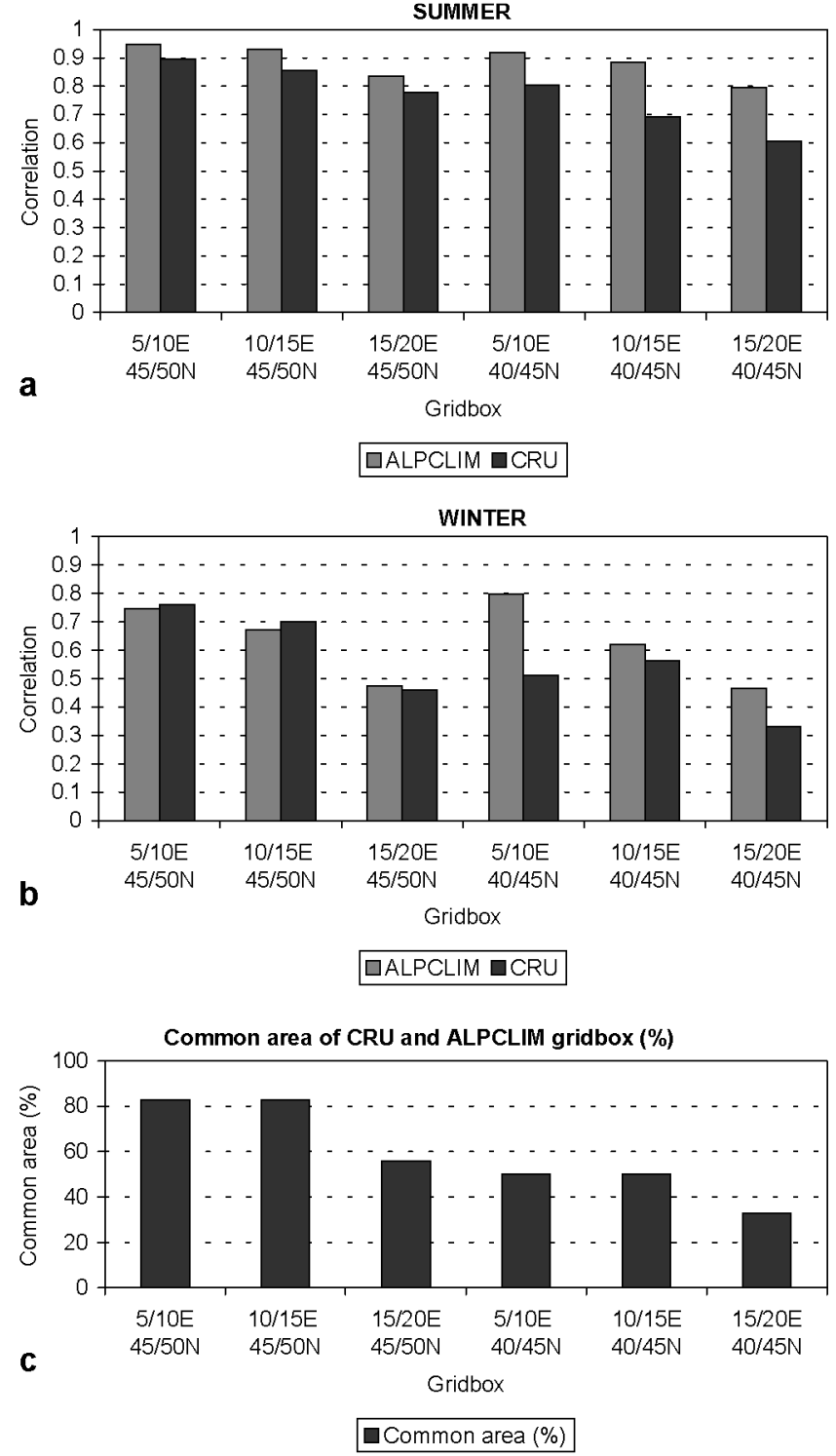

Fig. 3. Correlation between Colle Gnifetti temperature and ALPCLIM gridbox temperature in comparison to correlation between Colle Gnifetti temperature and CRU gridbox temperature for summer $(a)$ and winter $(b)$. (c) Commonarea coverage of ALPCLIM and CRU gridboxes.

signal persistence for the directions west (weather types with cyclones from west to northwest) and northeast (weather types with continental high during winter).

The difference between ALPCLIM and CRU airtemperature series (ALPCLIM minus CRU) for common gridbox 10/15E 45/50N (covering the southern part of Germany, parts of the Central and Eastern Alps and the Po plain) shows a strong temporal trend (Fig. 2). This contributes about $0.8^{\circ} \mathrm{C}$ between 1940 and 1990 and is significantly larger than the last 100 years linear warming trend of $0.5^{\circ} \mathrm{C}$ inherent in the CRU dataset. As shown by Böhm and others (2001), the CRU dataset features several inhomogeneities which can explain the differences with the ALPGLIM dataset. Homogeneity problems with the CRU gridded temperature dataset are also reported for other regions by Moberg and Alexandersson (1997).

Figure 3 shows a comparison of spatial correlation between ALPCLIM Colle Gnifetti temperature series and CRU and ALPCLIM common gridboxes for the period 


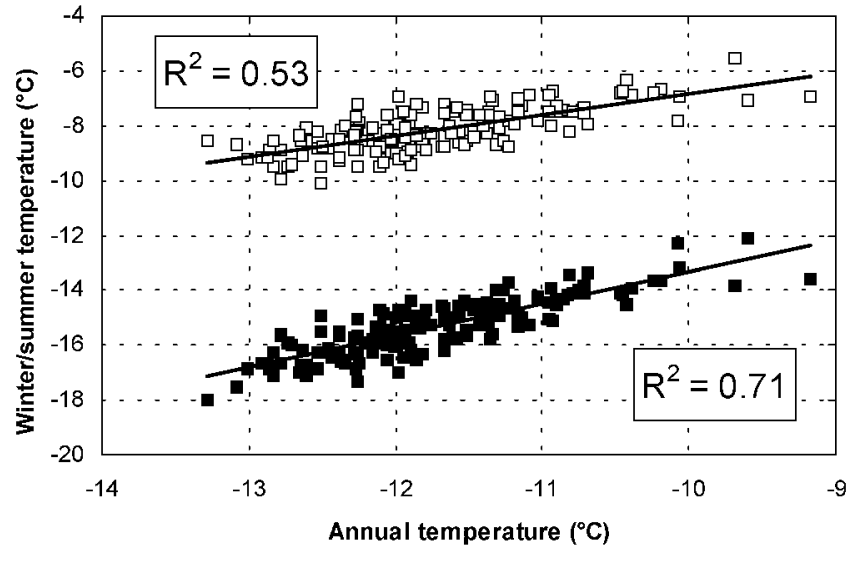

a Summer a Winter —_Linear (Winter) _ L Linear (Summer)

Fig. 4. Regression between annual temperature and seasonal temperatures calculated from the ALPCLIM dataset for the Colle Gnifetti gridbox ( $R^{2}$ means explained variance). Above: summer; below: winter.

1901-98. Note the variations in the common area of the CRU and ALPCLIM gridboxes (Fig. 3c). Differences in spatial correlation are higher during winter, and close to statistical significance for gridboxes with a higher common-area ratio. We conclude that inhomogeneities in the GRU data series do not systematically influence correlation results and derived statements about spatial representativity.

\section{SEASONAL GORRELATION OF INSTRUMENTAL AIR TEMPERATURE}

In order to determine the representativity of seasonal temperature series for the annual temperature variability, the relation between summer temperature and annual temperature and between winter temperature and annual temperature was compiled for the CG air-temperature series (see Fig. 4). Though the CG air-temperature series appears to be more closely correlated to the winter series than to the summer ones, the correlation coefficient of $0.73\left(\mathrm{R}^{2}=0.53\right)$ between summer and annual series indicates that summer temperature variability provides an adequate approach to annual temperature variability.

\section{SPECIFIC FEATURES OF ISOTOPE REGORDS IN ALPINE ICE GORES}

As shown in Figure 5, the seasonal apportionment of the conserved fraction of precipitation in a high-Alpine ice core may be roughly estimated by comparing its mean $\delta^{18} \mathrm{O}$ value with the expected typical winter and summer $\delta^{18} \mathrm{O}$ levels at the site. The wide range of $\delta^{18} \mathrm{O}$ core means can only be explained by extreme differences in the recorded section of the year. However, the core means approach the expected summer level for low accumulation rates (BSK in Fig. 5), indicating that the latter almost exclusively conserve the precipitation of summer months. Note that due to the wide range of snow-accumulation rates the long-term precipitation rate is assumed to be similar at all investigated drill sites. This wide range in the mean accumulation rate is directly linked to the snow-erosion rate. Long-term Alpine ice-core records over at least several centuries (Wagenbach

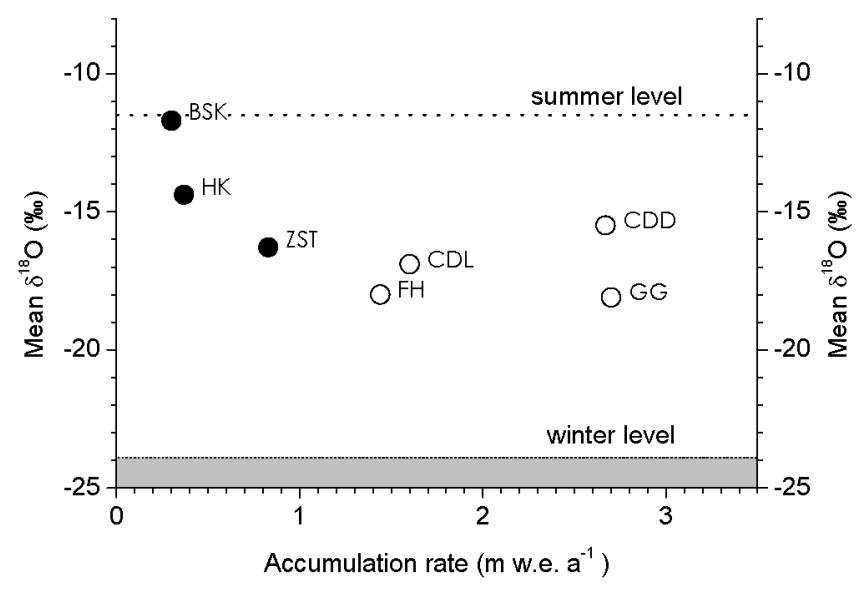

Fig. 5. Comparison of estimated typical summer and winter $\delta^{18} O$ levels at Colle Gnifetti with the mean $\delta^{18} O$ values from the 1983-91 time slices of three cores (BSK, HK and ZST) from Colle Gnifetti (dots) and with $\delta^{18} O$ core mean (circles) from: Col du Lys (CDL), Monte Rosa (personal communication from B. Stenni, 2001); Grenzgletscher (GG), Monte Rosa (Eichler and others, 2001); Fiescherhorn (FH), Bernese Alps (Schotterer and others, 1997); and Col du Dome (CDD), Mont Blanc region (Preunkert and others, 2000). The estimated summer level of $\delta^{18} O$ is calculated from fresh snow samples at Colle Gnifetti, and the winter level from snow pits in the Monte Rosa region (Stichler and others, 1998). All levels are corrected by an altitude effect of $0.2 \% 0(100 \mathrm{~m})^{-1}$ (Schotterer and others, 1997) to 4500 m a.s.l.
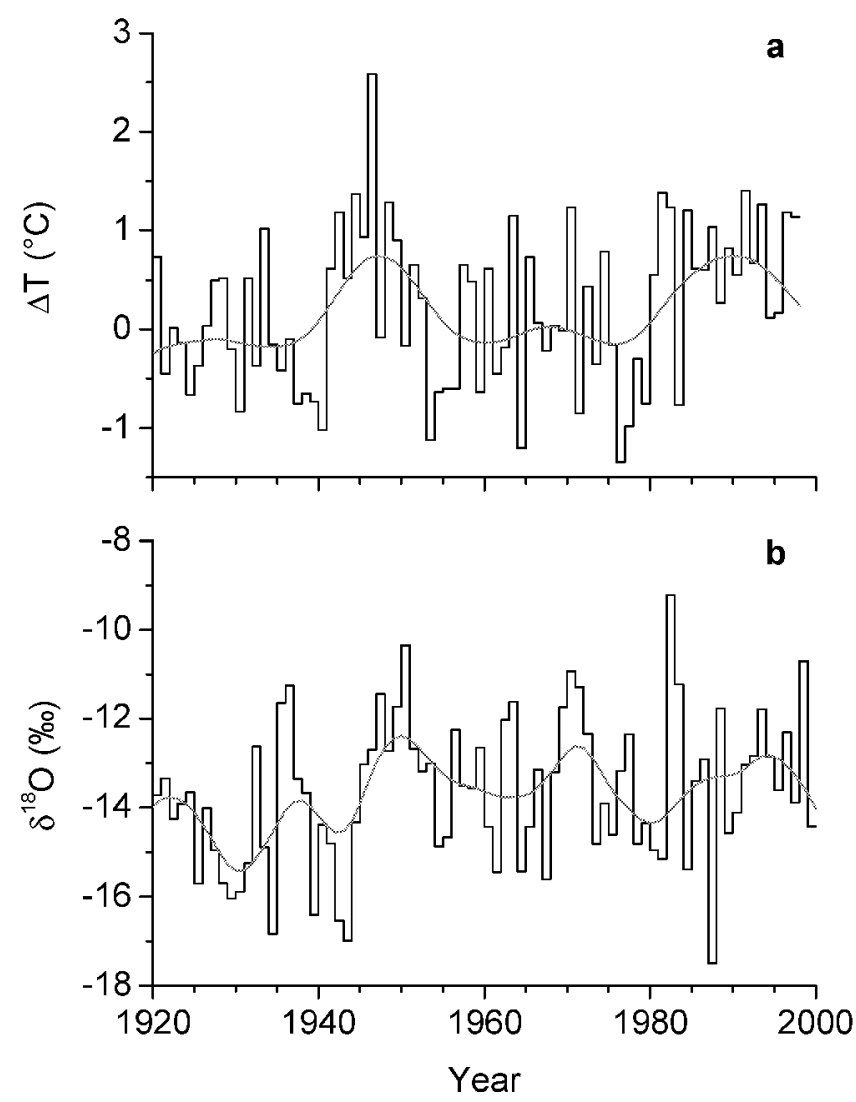

Fig. 6. Comparison of individual years and decadal trends in (a) instrumental summer temperatures (near Colle Gnifetti high-level gridpoint of the homogenized ALPCLIM records) and ( $b$ ) formal annual means derived from a $\delta^{18} O$ record icecore record at the drill site. 
and Preunkert, 1996) are expected to reflect predominantly summer conditions since they can only be obtained from low-accumulation sites.

\section{GOMPARISON OF ICE-CORE $\delta^{18} \mathrm{O}$ WITH INSTRUMENTAL TEMPERATURE RECORDS}

Ice-core climate proxy records from European high-Alpine sites offer the unique possibility of a comparison to longterm instrumental temperature time series. As outlined, it is most appropriate to compare ice-core records from lowaccumulation sites with summer temperatures. Figure $6 \mathrm{a}$ and b show the 80 year record of formal annual $\delta^{18} \mathrm{O}$ means derived from an ice core drilled in a low-accumulation area $\left(0.25 \mathrm{~m}\right.$ w.e. $\left.\mathrm{a}^{-1}\right)$ at Colle Gnifetti, along with the GG instrumental air temperatures. The large deviations between the individual years of the two time series are caused by the dating uncertainty of up to 3 years (Armbruster, 2000) as well as by depositional noise. By contrast, decadal trends of temperature and $\delta^{18} \mathrm{O}$ records (emphasized by a robust cubic-spline smoothing) are in fairly good agreement.

\section{IMPLICATIONS FOR ALPINE IGE-GORE PROXY TEMPERATURE}

Long-term stable-isotope records from Alpine ice cores consist mainly of summer precipitation and thus reflect long-term trends in local high-elevation summer air temperature. The high correlation between high-Alpine air temperatures and central European lowland temperatures in summer implies that the ice-core temperature proxy data may approach the long-term central European summer temperature variability. Moreover, as high-Alpine summer temperatures are correlated to annual temperatures, information on trends in annual temperatures may be derived from Alpine ice-core records as well, though with a confined spatial representativity.

The typically conserved section of the year differs greatly from site to site and may systematically change over a multi-centennial time period. In view of the good spatial correlation during all seasons, this would be expected to have a minor impact on the spatial representativity of Alpine ice-core records.

\section{AGKNOWLEDGEMENTS}

The ALPCLIM project is funded by the European Community (ENV4-CT97-06389). We are grateful to the Laboratoire de Glaciologie et Géophysique de l'Environnement, Saint-Martin-d'Hères, France, to the Centre des Faibles Radioactivités, Gif-sur-Yvette, France, and to B. Stenni for providing us with unpublished data.

\section{REFERENGES}

Alean, J., W. Haeberli and B. Schädler. 1984. Snow accumulation, firn temperature and solar radiation in the area of the Colle Gnifetti core drilling site (Monte Rosa, Swiss Alps): distribution patterns and interrelationships. Z. Gletscherkd. Glazialgeol., 19(2), 1983, 131-147.

Armbruster, M. 2000. Stratigraphische Datierung hoch-alpiner Eisbohrkerne über die letzten 1000 Jahre. (M.Sc. thesis, Universität Heidelberg. Institut für Umweltphysik.)

Auer, I., R. Böhm, W. Schöner and M. Hagen. 1999. ALOCLIMAustrian-central European long-term climate. Creation of a multiple homogenized long-term climate data-set. In Szalai, S., T. Szentimrey and C. Szinell, eds. Second Seminar for Homogenisation of Surface Climatological Data. Proceedings. Budapest, Hungarian Meteorological Service, 47-71. (WMO WCDMP 41, WMO-TD 962.)

Auer, I., R. Böhm andW. Schöner. 200la. Austrian long-term climate: multiple instrumental climate time series in central Europe (1767-2000). Österreich. Beitr. Meteorol. Geophys. 25.

Auer, I., R. Böhm and M. Mangeri. 200lb. A new long-term gridded dataset for the Alps and its application for Map and Alpclim. Phys. Chem. Earth (B), 26(5-6), 421-424.

Böhm, R., I. Auer, M. Brunetti, M. Maugeri, T. Nanni and W. Schöner. 2001. Regional temperature variability in the European Alps 17601998. Int. F. Climatol., 21, 1779-1801.

Eichler, A., M. Schwikowski and H.W. Gäggeler. 2001. Meltwater-induced relocation of chemical species in Alpine firn. Tellus, 53B(2), 192-203.

Jones, P. D. 1994. Hemispheric surface temperature variations: a reanalysis and an update to 1993. F. Climate, 7(11), 1794-1802.

Jouzel, J. and 12 others. 1997. On the validity of the temperature reconstruction from water isotopes in ice cores. F. Geophys. Res., 102(C12), 26,471-26,487.

Moberg, A. and H. Alexandersson. 1997. Homogenisation of Swedish temperature data. Part 2. Homogenised gridded air temperature compared with a sub-set of global gridded air temperature since 1861. Int. 7. Climatol., 17, 34-54.

Peterson, T. C. and 16 others. 1998. Homogeneity adjustments of in situ climate data: a review. Int. 7. Climatol., 18, 1493-1517.

Preunkert, S., D. Wagenbach, M. Legrand and C. Vincent. 2000. Col du Dôme (Mt Blanc Massif, French Alps) suitability for ice core studies in relation with past atmospheric chemistry over Europe. Tellus, 52B(3), 993-1012.

Schotterer, U., K. Fröhlich, H.W. Gäggeler, S. Sandjordj and W. Stichler. 1997. Isotope records from Mongolian and Alpine ice cores as climate indicators. Climatic Change, 36, 519-530.

Stichler, W. and 6 others. 1998. Spatial and seasonal variability of isotopic properties of the winter snow pack at high Alpine elevation. In Isotope techniques in the study of environmental change. Vienna, International Atomic Energy Agency, 93-106. (Proceedings Series.)

Wagenbach, D. 1994. Special problems of mid latitude glacier ice core research. In Haeberli, W. and B. Stauffer, eds. Greenhouse gases, isotopes and trace elements in glaciers as climatic evidence of the Holocene. Report of the ESF/EPC Workshop, Zürich 27-28 October 1992. Zürich, EidgenössischeTechnische Hochschule. Versuchsanstalt für Wasserbau, Hydrologie und Glaziologie, 10-14. (Arbeitsheft 14.)

Wagenbach, D. and S. Preunkert. 1996. The history of European pollution recorded in Alpine ice cores. In Borell, P. M. and others, eds. Proceedings of EUROTRAC Symposium '96 Mediterranean. Southampton, Computational Mechanics Publications, 273-281.

Wagenbach, D. and 7 others. 1998. Environmental and climate records from high elevation Alpine glaciers (ALPCLIM). In European Climate Science Conference, 19-23 October 1998, Vienna. Proceedings. Vienna, European Commission. Austrian Federal Ministry of Science and Transport, CD-ROM. 